See discussions, stats, and author profiles for this publication at: https://www.researchgate.net/publication/322259470

\title{
Relevant Recruiting for Online Survey Participation
}

Book · January 2018

DOI: $10.4135 / 9781526438027$

3 authors, including:

Hannah Brenkert-Smith

University of Colorado Boulder

26 PUBLICATIONS 421 CITATIONS

SEE PROFILE

Nicholas E. Flores

University of Colorado Boulder

51 PUBLICATIONS 2,328 CITATIONS

SEE PROFILE 


\section{@SAGE researchmethods cases}

\section{Relevant Recruiting for Online Survey Participation}

Contributors: Hannah Brenkert-Smith, Katherine Dickinson \& Nicholas Flores

Pub. Date: 2018

Access Date: March 9, 2018

Academic Level: Postgraduate

Publishing Company: SAGE Publications Ltd

City: London

Online ISBN: 9781526438027

DOI: http://dx.doi.org/10.4135/9781526438027

C2018 SAGE Publications Ltd. All Rights Reserved.

This PDF has been generated from SAGE Research Methods Cases. 


\begin{abstract}
Administering a survey online has a number of practical benefits including lower costs, reductions in paperuse and data entry time, and a faster data collection time period. A significant challenge, however, entails creating and recruiting a relevant sample of respondents with specific characteristics when email lists are unavailable. In this case, we seek to encourage researcher conversation about relevant and effective recruitment strategies by describing the extensive pretesting process we undertook to develop our survey sampling and recruitment strategy for a study of wildfire mitigation behaviors in Western Colorado. Pretesting response rates varied from $3 \%$ to $30 \%$, with the inclusion of a US $\$ 2$ billion in the recruitment envelope yielding the highest response rate. The actual study subsequently used this approach and resulted in a $35 \%$ response rate.
\end{abstract}

\title{
Learning Outcomes
}

By the end of this case, students should be able to

- Identify possible challenges to constructing a relevant population sample when conducting a survey online

- Articulate potential challenges of online survey participation using a mail recruitment tool

- Start to identify creative solutions to overcome recruitment challenges for recruiting for online survey

\section{Project Overview and Context: Defining the Problem}

Understanding the social dynamics of natural resource and natural hazard dilemmas often requires collecting data from the people whose beliefs, behaviors, and perspectives influence problem framing, management, and resolution. In the case of wildfire, property owners' risk reduction decisions in the areas where wildland and private properties meet, the wildland-urban interface (WUI), play an important role in wildfire outcomes. Responsiveness to a survey on a salient topic is expected to be higher than to a topic that isn't salient. However, responsiveness to recruitment for proposed research can only be based on an informed guess unless one has been engaged in on-going research on the specific topic or in a specific geographic area. Although secondary data sources (e.g., Census data) may provide some basic information about the population affected by a particular natural resource/hazard dilemma, these data sources are often inadequate for more in-depth analyses of the social dynamics surrounding such dilemmas. Further inquiry into natural resource/hazard beliefs and behaviors typically requires collecting primary data from relevant publics.

When pursuing insights into socially and geographically specific dilemmas, in-person data collection is often a preferred approach; however, the time and cost requirements of such efforts often limit sample sizes. And yet, the administration of surveys to a broader, more representative sample of the relevant public presents a number of challenges, perhaps the greatest of which is obtaining adequate response rates from a population that is relevant to the natural resource or natural hazard dilemma.

Research Practicalities: Defining the Population

We sought to conduct an online experiment and survey with property owners whose decisions influence 
wildfire outcomes. In other words, we sought to collect data from property owners whose attitudes, beliefs, behaviors, and choices were directly relevant to wildfire and forest management policy and programs. In addition to its potential cost and time savings, an online survey was particularly desirable in our context because one key section of our survey, a choice experiment, required the randomization of survey components (choice tasks) across participants and the presentation of visually rich materials.

Our study takes place in Colorado, one of the fastest growing states in the United States with much of this growth occurring outside urban boundaries. This increase in population across the state affects counties and communities located within the WUI. The WUI is described as the area where structures and other human improvements meet and intermingle with undeveloped wildland or vegetative fuels (Stewart, Radeloff, Hammer, \& Hawbaker, 2007). Population growth within the WUI substantially increases the risk from wildfire for a number of reasons, including increased exposure to wildfire hazards.

Although the topic of wildfire may be widely salient, recruiting within the target population presents a number of significant methodological challenges. First, pre-existing email lists for such a population do not exist. Second, property owners whose decisions influence wildfire outcomes are located in rural areas characterized by vast and varied landscapes that are primarily forested, but include agricultural lands and urban spaces. As such, not all property owners live in fire-prone areas. And finally, the rural West is noted, as is much of rural United States, for varied and often poor Internet connectivity (Pereira, 2016). To tackle these challenges, we undertook a Geographic Information Systems (GIS) mapping process, drawing on multiple data sources to construct the sampling frame. ${ }^{1}$ GIS mapping provides a platform upon which spatial or geographic data can be layered to visualize opportunities to merge data sets (Mitchell, 1999). In this case, multiple data sets, described briefly below, were used to identify private property characterized by high wildfire risk and with adequate Internet coverage to participate in an online study.

\section{Parcel Data}

To build a sampling frame of privately owned residential parcels west of the Continental Divide in Colorado, we began with parcel data. Parcel data are a way of describing and characterizing a landscape delineated by legal ownership boundaries. County Assessor Offices typically maintain parcel data sets for the purposes of property tax collection. We began by collecting parcel data from county Assessor Offices for each of the 16 counties in the study area. A total of 10 of the 16 counties had GIS parcel data available to initiate the mapping process. Figure 1 shows a Colorado map with the study area, types of parcel data available by county, and the 10 (starred) counties with adequate data for the survey. 
Figure 1. Map of Colorado counties and data availability.

\section{Western Slope Counties Classifications}

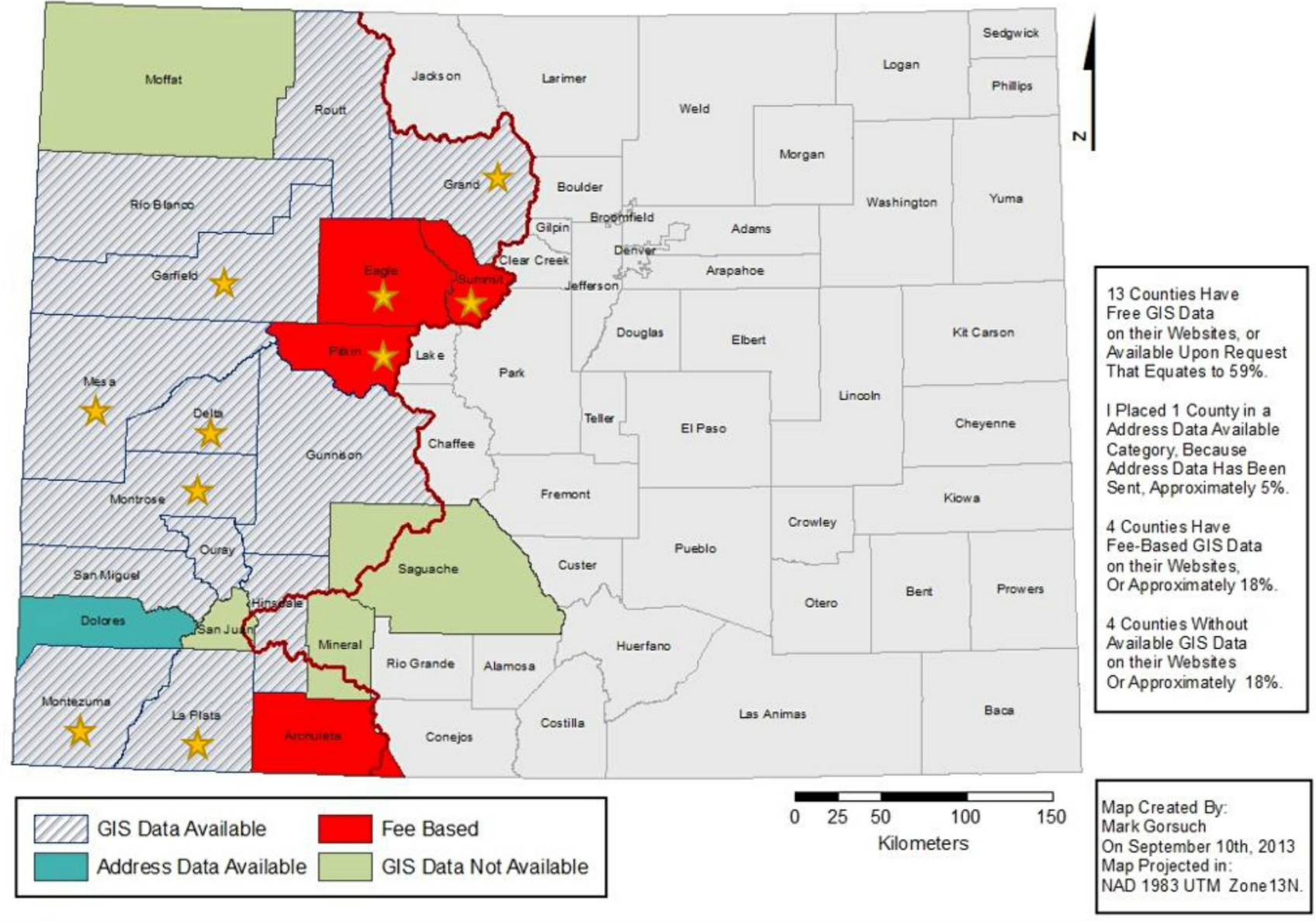

Once parcel data were mapped, additional GIS layers were added to facilitate the development of a study population of all privately owned residential parcels (with an existing structure) at risk of wildfire damages or losses in the WUI in the western half of Colorado.

GIS data layers from Colorado Wildfire Risk Assessment Portal (CO-WRAP) provided uniform wildfire risk data across the entire state of Colorado. Using the CO-WRAP data, we were able to limit our sample to a population whose actions are critical to wildfire management based on housing density and fire risk GIS data layers.

Acquiring a successful response rate with an online survey requires that areas sampled have adequate Internet accessibility. As the cellular network-connected mobile devices (smartphones and tablets) are becoming increasingly widespread, opportunities for conducting online surveys are growing. In these cases, maps of cellular network coverage may also be informative in selecting potential sample areas, and attention must be paid that surveys are mobile-compatible. The western portions of Colorado are characterized by limited urban development, and related infrastructure is also lacking in many areas as public lands, agriculture, and extraction economies dominate the region (http://www.fcc.gov/document/fcc-launches-ninthinquiry-broadband-availability). Data available from the Federal Communication Commission (FCC) were 
used to map Internet availability and exclude parcels in areas without adequate coverage. All parcels in areas with lower levels of Internet availability were excluded from the sampling frame due to concerns about the likelihood of successful recruitment in those areas. For the purposes of building the sampling frame, we selected parcels in areas that had at least 400 connections per 1,000 households at the 768-kbps downstream speed. The 768-kbps download speed reflects a typical digital subscriber line (DSL) connection that can be acquired through a phone line. Although it is not the bare minimum of a dial-up connection, it is at the lowest end of current broadband technology and speed.

For each of the data layers, we retained values for each parcel included in the sampling frame (parcel property characteristics, housing density, fire risk, and level of Internet coverage). These values are associated with each potential recruit and are available for use as covariates in the data analysis portion of the project.

Research Design: Sampling

Having constructed the sampling frame using the criteria described above, we used a random number generator to draw a random sample from each of 10 western slope Colorado counties such that the sample size was proportional to the eligible population in each county.

\section{Pretesting for an Effective Recruitment Strategy}

As recruitment and study participation involved two different media (recruitment letter followed by online response), it was imperative to identify the best recruitment strategy. Unlike in a situation in which respondents are recruited via email to take an online survey and can simply click on a link, we needed respondents to actually type the survey URL into their browser. We thus needed a URL that met two key requirements. First, the URL had to be short, easy to read and simple to copy accurately. Second, we needed the URL to be trustworthy and legitimate-looking because many users may be concerned about online security and unknown web addresses. As such, we arranged for the University of Colorado to host a webpage http://www.colorado.edu/firesurvey (see Figure 2) with links to the Qualtrics-hosted survey (both computer and mobile-formatted versions). 
Figure 2. Image of simple, trustworthy URL used for survey recruitment. Contains links for computer or mobile options for participation.

कृ Wildfire Sunvey | Universi $x$

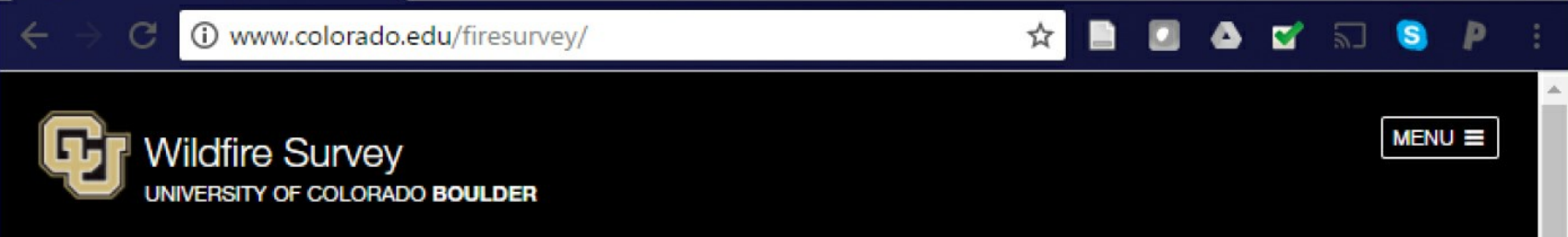

\section{Wildfire! Tell us what you think.}

Wildfire is an ongoing problem across Colorado.

\section{Will you participate in a survey about wildfire risk?}

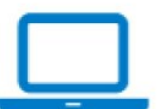

On your computer

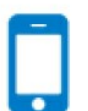

On your mobile

\section{Wildfire Survey}

Questions? Please contact:

Hannah Brenkert-Smith

hannahb@colorado.edu

303-492-5743

\section{Be Boulder}

Our original data collection schedule entailed a pretesting process in fall 2014 with intent to administer the survey through the 2014-2015 winter. However, the first pretest made it clear that our original plan to recruit study participants via postcard was not going to yield an adequate response, and that additional pretesting was required to identify an effective recruitment strategy. See Table 1 for details on our pretesting details and response rates.

Table 1. Pretest details and responses.

\begin{tabular}{|l|l|l|l|l|}
\hline Pretests & Format details & Mailing dates & Mailing details $\begin{array}{l}\text { Response } \\
\text { rate (\%) }\end{array}$ \\
\hline & & October 2, 2014 & 131 delivered & \\
\hline
\end{tabular}




\begin{tabular}{|c|c|c|c|c|}
\hline $\begin{array}{l}\text { Pretest } 1 \\
(n=140)\end{array}$ & Postcard; reminder postcards & $\begin{array}{l}\text { October 10, } 2014 \\
\text { October 20, } 2014\end{array}$ & $\begin{array}{l}9 \text { returned } \\
4 \text { completed }\end{array}$ & 3.05 \\
\hline $\begin{array}{l}\text { Pretest } 2 \\
(n=100)\end{array}$ & Invitation letter; 2 follow-up reminder letters & $\begin{array}{l}\text { October } 23,2014 \\
\text { November } 03, \\
2014 \\
\text { November } 10, \\
2014\end{array}$ & $\begin{array}{l}79 \text { delivered } \\
21 \text { returned } \\
11 \text { completed } \\
3 \text { incompletes }\end{array}$ & 13.9 \\
\hline $\begin{array}{l}\text { Pretest } 3 \\
(n=100)\end{array}$ & $\begin{array}{l}\text { Invitation letter with US\$2 incentive; } 2 \text { follow-up } \\
\text { reminder letters }\end{array}$ & $\begin{array}{l}\text { November } 21, \\
2014 \\
\text { December } 3, \\
2014 \\
\text { December } 12, \\
2014\end{array}$ & $\begin{array}{l}86 \text { delivered } \\
14 \text { returned } \\
26 \text { completed }\end{array}$ & 30 \\
\hline $\begin{array}{l}\text { Pretest } 4 \\
(n=100)\end{array}$ & $\begin{array}{l}\text { Invitation letter with return postcard for paper } \\
\text { survey; follow-up reminder letter with return } \\
\text { postcard }\end{array}$ & $\begin{array}{l}\text { November } 21, \\
2014 \\
\text { December } 3, \\
2014 \\
\text { Paper survey } \\
\text { mailed upon } \\
\text { request }\end{array}$ & $\begin{array}{l}81 \text { delivered } \\
19 \text { returned } \\
5 \text { c a r d s } \\
\text { requesting } \\
\text { paper survey } \\
10 \text { completed }\end{array}$ & 12 \\
\hline $\begin{array}{l}\text { Pretest } 5 \\
(n=50)\end{array}$ & $\begin{array}{l}\text { Letter with US } \$ 1 \text { incentive; follow-up reminder } \\
\text { letter }\end{array}$ & $\begin{array}{l}\text { December } 12, \\
2014 \\
\text { December 23, } \\
2014\end{array}$ & $\begin{array}{l}45 \text { delivered } \\
5 \text { returned } \\
3 \text { completed }\end{array}$ & 6 \\
\hline
\end{tabular}

Our initial pretest (October 2014) included 140 potential respondents from our 10 study counties, proportional to county populations as was planned for the full survey mailing. After setting up the online instrument, we mailed brightly colored, $5^{\prime \prime} \times 7^{\prime \prime}$ postcards to the 140 recruits, with two follow-up postcards (identical to the original) sent 1 and 2 weeks after the initial mailing. Finding that by the end of the month we had only attained a $3.05 \%$ response rate, we concluded that postcards were less likely to draw the attention of potential participants than a standard letter. As such, we altered our approach.

Pretest 2 (October to November 2014) used a standard approach described by Dillman (2000), with an initial 
letter of invitation and two follow-ups 7 to 10 days later. As we were concerned about the pretest process depleting our recruitment budget, we reduced the number of recruits at this stage to 10 per county $(n=100)$. This approach yielded a much improved response rate of roughly $14 \%$, but still not one adequate for our purposes.

Being a month behind schedule at this point, we launched Pretests 3 and 4 simultaneously in November to December 2014, hoping to answer two questions. For Pretest 3, we were testing whether a small monetary incentive might change the response rate. We maintained a sample of 10 recruits per county and sent letters maintaining the approach described by Dillman (2000). In this pretest, however, we included a US $\$ 2$ billion in the first recruitment letter as an incentive and token of thanks. We saw the response rate increase to $30 \%$.

As we had received some calls and emails during Pretests 1 to 2 indicating a preference for paper surveys, Pretest 4 tested whether we could recruit online participants while also providing a paper option to those with this preference. In this pretest, we sent a letter with all the information to participate in the online survey along with a stamped return postcard by which recruits could indicate they would take a paper survey. For Pretest 4, we mailed paper surveys upon request and yielded a 12\% response rate. Only one follow-up letter was sent to this group, due to the fact that it was quickly becoming evident that the simultaneously mailed Pretest 3 was yielding a higher response rate.

Curious about the added value and novelty of the US $\$ 2$ billion, and interested in reducing costs if possible given our budget and target sample size of 1,000 respondents, we launched one final pretest (December 2014) using only a US $\$ 1$ incentive. Our results clearly showed that this incentive was much less effective; the response rate for Pretest 5 (after one follow-up letter) was just 6\%-less than half of the response rate from the identical approach without any monetary incentive (Pretest 2). We thus abandoned the third mailing for Pretest 5 and settled on the Pretest 3 method as our preferred recruitment strategy.

\section{Method in Action: From Pretest to Full Recruitment}

After this extensive pretesting, we finally launched the survey to 4,000 potential respondents starting 20 January 2015 using the recruitment strategy from Pretest 3 . All initial letters of invitation included a US $\$ 2$ incentive to encourage survey participation. As with the pretesting, first-class postage was used to ensure that return services would allow us to track undeliverable mail as accurately as possible.

The website was monitored daily beginning on January 22, 2015 for responses. Unique ID codes printed on each letter were used by participants to log in to the survey. This allowed us to track responses and remove participants who had completed the survey from follow-up mailing lists. Emails and phone calls were received from participants throughout the mailing period, which included basic queries regarding how to find the survey online, how to log on, or the broader intent of the survey.

Despite our sampling strategy to ensure Internet availability, we received several calls from potential participants indicating they lacked access to a computer or to the Internet. Multiple letters were also received from potential participants with notes enclosed indicating the same. We sent paper surveys to everyone who contacted us regarding a lack of computer or Internet access. 
Follow-up letters were mailed on February 6, $2015(n=3,442)$. Return service on these letters was not requested to achieve cost savings of US\$0.49/letter. Most responses were obtained via the first two mailings. However, a third and final mailing was sent on March 18, 2015 to non-respondents $(n=2,652)$. Ultimately, our recruitment strategy resulted in a 35\% response rate, yielding 1,175 completed responses (see Table 2 for survey recruitment and response by county).

Table 2. Details of survey recruitment and response by county.

\begin{tabular}{|l|l|l|l|l|l|l|l|l|l|}
\hline County & $\begin{array}{l}\text { Eligible } \\
\text { parcels } \\
\text { (sampling } \\
\text { frame) }\end{array}$ & Mailed & Returned & $\begin{array}{l}\text { Total } \\
\text { delivered }\end{array}$ & $\begin{array}{l}\text { Delivery } \\
\text { rate (\%) }\end{array}$ & Responses & $\begin{array}{l}\text { Response } \\
\text { rate }{ }^{\text {(\%) }}\end{array}$ & $\begin{array}{l}\text { Completed } \\
\text { responses }\end{array}$ & $\begin{array}{l}\text { Completed } \\
\text { response } \\
\text { rate }\end{array}$ \\
\hline Delta
\end{tabular}

a Response rate accounts for all respondents who logged onto the survey with their unique user ID and initiated the survey process.

b Completed response rate accounts for all respondents who reached the end of the survey and for which data are usable. 
' Montrose county: Assessor database did not include owners' names; as such, recruitment letters were sent to "Montrose County Resident" instead of being personalized. The response rate $(19.4 \%)$ is notably lower than for other counties for which the average response rate is $35 \%$.

$d$ These respondents used an alternative identification code to log on to the online data collection tool. The county of residence for these respondents cannot be known since the ID codes were enumerated to indicate county of residence.

\section{Practical Lessons Learned}

Budget time and costs for multiple rounds of pretesting.

Be creative in considering multiple data sources to build a relevant sampling frame.

Create a plan to attend to those who cannot respond online.

\section{Conclusion}

Developing an effective strategy for online survey data collection presents challenges that include defining the study population and finding a recruitment strategy that yields an adequate response rate. Here, we have described the central obstacles we faced and the steps undertaken to address them. However, additional challenges remain, including Internet literacy. Despite having used an easy-to-type, legitimatelooking University (colorado.edu) URL, early in the pretesting process, we learned that some potential recruits didn't understand instructions regarding how to enter an address into a web browser. As such, the pretesting process allowed us to revise our letters to include an image of the survey address in a web browser. We still received numerous calls from individuals who required additional guidance.

We also acknowledge that even the most well-designed mail recruitment strategy may run up against challenges in recruiting individuals for online surveys. These challenges include general "survey fatigue" from increased presence of marketing surveys (Groves et al., 2004; Porter, Whitcomb, \& Weitzer, 2004). Furthermore, there may be specific cultural barriers in some contexts leading to lower response rates. Research characterizing social dimensions of the rural west highlights that community types may vary widely in their willingness to trust outsiders, including the government (Carroll \& Paveglio, 2016). This lack of trust has implications for the likelihood of opening mail as well as willingness to log on to an unfamiliar website.

These issues aside, do we think that the US\$2 billion is a "magic bullet" for survey recruitment? Although it is possible that a larger incentive would have further increased response rate (Edwards et al., 2002), our (and others') research budgets do not always allow for such expenditures. We considered the enclosure of other types of token incentives, like pens or other mementos from the university, but felt such branded mementos would run the risk of eliciting negative responses from some respondents depending on their attitudes toward the organization. Side-by-side comparisons of different types of incentives would be informative for the field of survey research. More generally, we find that frank and detailed discussions with colleagues regarding these processes help the research community undertake our work more effectively and with greater insight. 
1. As with any study, potential recruits were also screened to ensure they met basic Human Subjects Review requirements include age and consent procedures and protections regarding study subject participation.

\section{Exercises and Discussion Questions}

Exercise: Use the lessons from this case study and work through how you might engage in relevant recruitment, using an online survey, for one of these scenarios:

1.Water use and water quality concerns among small farmers in Tennessee.

2.Water quality and environmental health of rivers among recreational fishermen in Montana.

3.Health concerns among miners working in West Virginia and Pennsylvania.

Related questions:

1.Describe the key challenges in identifying your study population.

2.What resources might you use to construct a sampling population? What data layers would you need, and where might you find these?

3.Develop three recruitment strategies that might be useful to ensure an appropriate response rate.

\section{Further Reading}

Cook, C., Heath, F., \& Thompson, R. L. (2000). A meta-analysis of response rates in web-or internet-based surveys. Educational and Psychological Measurement, 60, 821-836.

Dillman, D. A., \& Bowker, D. K. (2001). The web questionnaire challenge to survey methodologists. In B. Batinic, U. D. Reips, M. Bosnjak, \& A. Werner (Eds.), Online social sciences (pp. 53-71). Seattle, WA: Hogrefe \& Huber.

Evans, J. R., \& Mathur, A. (2005). The value of online surveys. Internet Research, 15, 195-219.

Fan, W., \& Yan, Z. (2010). Factors affecting response rates of the web survey: A systematic review. Computers in Human Behavior, 26, 132-139.

Fleming, C. M., \& Bowden, M. (2009). Web-based surveys as an alternative to traditional mail methods. Journal of Environmental Management, 90, 284-292.

Kaplowitz, M. D., Hadlock, T. D., \& Levine, R. (2004). A comparison of web and mail survey response rates. Public Opinion Quarterly, 68, 94-101.

Shih, T. H., \& Fan, X. (2009). Comparing response rates in e-mail and paper surveys: A meta-analysis. Educational Research Review, 4, 26-40.

Toepoel, V. (2015). Doing surveys online. Thousand Oaks, CA: SAGE.

\section{Web Resources}

https://www.fcc.gov/document/fcc-launches-ninth-inquiry-broadband-availability

\section{References}


Carroll, M., \& Paveglio, T. (2016). Using community archetypes to better understand differential community adaptation to wildfire risk. Philosophical Transactions of the Royal Society B, 371, 20150344.

Dillman, D. A. (2000). Mail and Internet surveys: The tailored design method (Vol. 2). New York, NY: Wiley.

Edwards, P., Roberts, I., Clarke, M., DiGuiseppi, C., Pratap, S., Wentz, R., \& Kwan, I. (2002). Increasing response rates to postal questionnaires: Systematic review. British Medical Journal, 324, 1183.

Groves, R. M., Fowler, F. J., Couper, M. P., Lepkowski, J. M., Singer, E., \& Tourangeau, R. (2004). Survey methodology. Hoboken, $\mathrm{NJ}$ : Wiley.

Mitchell, A. (1999). The ESRI guide to GIS analysis: Geographic patterns \& relationships (Vol. 1). Redlands, CA: ESRI.

Pereira, J. P. R. (2016). Broadband access and digital divide. In A. Rocha, A. M. Correia, H. Adeli, L. P. Reis, \& M. Mendonça Teixeira (Eds.), New advances in information systems and technologies (pp. 363-368). Basel, Switzerland: Springer International Publishing.

Porter, S. R., Whitcomb, M. E., \& Weitzer, W. H. (2004). Multiple surveys of students and survey fatigue. In S. R. Porter (Ed.), New directions for institutional research, Issue 121: Overcoming survey research problems (pp. 63-74). San Francisco, CA: Jossey-Bass.

Stewart, S. I., Radeloff, V. C., Hammer, R. B., \& Hawbaker, T. J. (2007). Defining the wildland-urban interface. Journal of Forestry, 105, 201-207. 
